\title{
Preliminary Evidence for Infusing Mindfulness, Yoga and Parenting Education Training on the Resilience-building Capacity for Incarcerated Fathers
}

\author{
Jennifer K. Crawford, Gitanjali Shrestha, and Laura G. Hill \\ Washington State University
}

\begin{abstract}
Background and Purpose: Research has shown correlations between mindfulness, yoga and reduced risky behaviors among incarcerated and high-risk populations. Research has also shown that yoga can increase positive mental and physical health. Purpose: The present study extends current knowledge by combining a parenting program with yoga instruction in a 12-session series delivered to incarcerated fathers. We hypothesized that participants' resilience and parenting knowledge would increase from beginning to end of program. Methods: Using three measures for parental resiliency and one program scale for parenting, we assessed pretest to posttest changes in 65 of 112 criminal justice-involved fathers who completed a parenting curriculum that includes yoga and mindfulness instruction. Results: Participants significantly improved on two of three measures of resilience: overall Self Compassion Scale (SCS), and overall Whole Person Scale (WPS), which includes a total of three of six SCS subscales and three of four WPS subscales, from pretest to posttest; and on a parenting scale (Fit2bFathers Program Scale). Conclusion: The study provides preliminary evidence that a parenting program with yoga instruction may be an effective intervention for high-risk populations where parenting skills may be limited or stressed.
\end{abstract}

(C) 2015 Californian Journal of Health Promotion. All rights reserved.

Keywords: yoga, prevention programming, stress management, parenting, corrections

\section{Introduction}

A resilient person is one who can successfully navigate difficult life experiences, and emerge from these experiences a stronger and healthier individual. A resilient person does not simply bounce back, but bounces forward, transformed by the process of moving through personal challenges. This process involves decreasing stress, effectively solving problems, and building healthy relationships with others that result in positive changes and growth (Browne, 2014). Parental resilience specifically includes the ability to nurture children in the face of stressful situations, which in turn cultivates resilience in children as well. Parental resilience is recognized as one of five child abuse prevention protective factors, and has informed even broader policy and programming aimed at promoting healthy children and families (Browne, 2014).

A major factor in developing parental resilience is the experience of having been raised in a safe and nurturing environment. It has been argued that one of the greatest obstacles to advances in public health is that there is a "huge portion of the population that has had no experience with supportive parenting themselves" (Becker, 2015).

\section{Incarcerated Fathers}

This study focuses on criminal justice-involved fathers, who tend to have a history of poor parenting and other risk factors that, when left without interventions, can potentially produce a multi-generational cascade of low resilience and less effective parenting (Eddy et al. 2008). Many inmates develop maladjusted coping mechanisms, such as self-isolation (Haney, 2003 in Marlow et. al., 2011), that may exacerbate challenges of transitioning back into family life. 
On average, $75 \%$ of men incarcerated in jails and prisons are fathers (Kjellstrand \& Eddy, 2011). Family members of incarcerated parents also face negative health, social and economic consequences (Comfort, 2007; Kjellstrand \& Eddy, 2011). Further, punitive harsh and/or unpredictable discipline and control practices that are often characteristic in jails and prisons are contrary to what is known as best practices for healthy child development, parent/child relationships, discipline, and guidance (Comfort, 2007).

Cultivating resilience skills in incarcerated fathers can both help them adjust to life while incarcerated, and help them prepare for a criminal-free life post-incarceration. Additionally, appropriate interventions can have beneficial outcomes for their families as well. Interventions that target both parental resilience and parenting skills may be particularly effective in high-risk populations for promoting recognized and needed positive stress management skills. Positive family interaction during and after incarceration, particularly parent-child relationship quality, has been shown to reduce high-risk behaviors, recidivism, and future incarceration (Bahr, Armstrong, Gibbs, Harris, \& Fisher, 2008; Eddy, et. al., 2008).

\section{Father Involvement and Children's Outcomes}

Healthy father involvement is associated with multiple indicators for health and wellness including reduced risk for child abuse and neglect (Sedlak \& Broadhurst, 1996), fewer accidents (O’Connor, Davies, Dunn, \& Golding, 2000), and reduced risk for drug and alcohol abuse (Hoffmann, 2002; National Fatherhood Initiative, 2004; Phillips, Gleeson, \& WaitesGarret, 2009). Cultural changes in the roles of fathers, including greater expectations for father involvement in child rearing, are increasingly recognized to both challenge and positively influence men's personal growth, identity, and social development (Settersten \& Cancel-Tirado, 2010). Father involvement is also related to children's outcomes. Children with involved, well-adjusted, resilient fathers who display warmth are significantly more likely to be emotionally stable and positive (Cuffe, McKeown, Addy, \& Garrison, 2005), have healthy self-esteem, and exhibit empathy and pro-social behavior (Griffin, Botvin, Scheier, Diaz, \& Miller, 2000; Phillips, Gleeson, \& Waites Garrett, 2009).

\section{Mindfulness and Yoga-based Interventions for Criminal Justice-Involved Populations}

Mindfulness is an intentional practice of paying attention in the present moment in a nonjudgmental way (Kabat-Zinn, 1994; Howells, Tennant, Day, \& Elmer, 2010). Over the past fifteen years, mindfulness-based interventions and scientific publications on mindfulness have grown rapidly. An empirical review of multiple mindfulness-based interventions have shown that these interventions improve psychological health, with effects such as improved wellbeing, reduced reactivity, and improved behavior regulation (Keng, Smoski, \& Robins, 2011). These represent the same qualities of parental resilience: managing one's own personal stress in order to appropriately nurture, guide, model, and respond to children's needs. A review of eight randomized controlled trial studies of mindfulness and meditation interventions in correctional settings identified significant improvement across five variables related to mood, emotional outlook, and ability to relax (Shonin, Gordon, Slade, \& Griffiths, 2013).

\section{Mindfulness-based Interventions}

Mindfulness-based interventions for incarcerated populations have shown to reduce stress (Howells, Tennant, Day, and Elmer, 2010), reduce aggression (Fix \& Fix, 2013; Howells, Tennant, Day, \& Elmer, 2010; Samuelson, Carmody, Kabat-Zinn \& Bratt, 2007), and reduce substance use post-release (Bowen, et. al., 2006).

A significant component of many mindfulnessbased interventions is mindful movement, including the practice of yoga. Yoga, an alternative yet time-tested health practice that is rooted in centuries-old traditions (Duncombe, Kamorosky, Wong-Kim, \& Turner, 2005), is one of the top ten most popular complementary health practices in the United States (National 
Center for Complementary and Integrative Health [NCCIH], 2013). In the past ten years, the number of individuals who practice yoga has doubled from $5 \%$ to $10 \%$ of the U.S. population (NCCIH, 2013).

The Sanskrit origin of the word yoga means to yoke or to unite, pointing to the integrative aspect of yoga, which addresses wellness on physical, mental, emotional, and spiritual levels. Hatha yoga emphasizes mindful awareness of body, mind, breath, and spirit while practicing a sequence or series of physical postures. Its origins include philosophical teachings of nonviolence, and other moral guidelines for social behavior such as speaking truthfully, exercising appropriate control of the senses, honesty, generosity, and ethical principles including purity, contentment, discipline, self-study, and faith (Chopra \& Simon, 2004).

Published empirical studies of yoga, though smaller but growing in comparison to the large body of research on mindfulness, document its utility and applications in improved physical and mental health (Duncombe, Kamorsky, WongKim, \& Turner, 2005). These outcomes include increased self-esteem, reduced stress, reduced hostility, and reduced mood disturbance (Pilkington, Kirkwood, Rampes \& Richardson, 2005). Trauma-informed therapeutic yoga interventions have shown to effectively support individuals impacted by multiple adversities, including sexual abuse (Lilly \& Hedlund 2010), and post-traumatic stress disorder (Trauma Center at Justice Resource Institute, n.d). Practitioner scholars have encouraged incorporating yoga for clinical populations because of its potential to facilitate and enhance group learning (Rybak \& Deuskar, 2010).

Yoga is already incorporated into mindfulness interventions such as mindfulness-based stress reduction (MBSR) and mindfulness-based relapse prevention (MBRP) (Shonin, Van Gordon, Slade, \& Griffiths, 2013). Since sitting still may be difficult for individuals experiencing high levels of stress (Lilly \& Hedlund, 2010), the physicality of a yoga practice can provide an immediate engagement of the body that becomes both a focus of attention and a "felt experience" of connecting to body sensations. This "felt experience" is also used in experiential psychology as a mind-body self-help concept and tool to identify and relieve physical and emotional stress called "focusing" (The Focusing Institute, 2015).

Incorporating yoga into learning-focused, behavior-change interventions for criminaljustice populations in particular shows promise for facilitating physical health and mental wellbeing, and priming participants for learning and applying parenting skills taught in parenting education interventions. Mindfulness and yoga practiced each independently, as well as combined, can help cultivate self-regulation tools. Fathers who are able to practice selfregulation are then more likely to reduce further problems related to aggression even while still incarcerated and better avoid future criminal justice involvement. Fathers who can control their tempers and direct their attention towards healthy relationships with their children will increase changes for positive children's outcomes as well. To the authors' knowledge, no other studies have been conducted that specifically utilized a focused mindfulness or yoga intervention designed specifically for incarcerated fathers to date.

\section{The Current Study}

In the present study, we extended current knowledge by infusing a parenting program with mindfulness and yoga instruction in a 12session, 24-hour series delivered to incarcerated fathers. Based on the literature reviewed, we hypothesized that participants' resilience and parenting knowledge would increase from beginning to end of program.

\section{Methods}

\section{Participant Sample}

The current study used existing evaluation data from incarcerated Fit Fathers, Successful Families, Inside \& Out Program (FFSFIO) program participants who were fathers $(N=112)$ between July 2011 and June 2013, totalling fourteen implementations of the program. The program was also implemented in an alcohol and drug treatment center; however treatment center 
participants are not included in this program sample.

The jail education coordinator advertised the class as a voluntary option for inmates by posting flyers throughout the jail holding cells, or living quarters (also called tanks) and collecting interest sign-up sheets. The coordinator then selected group participants from the tank with the highest number of fathers and with the majority of inmates expected to remain within the tank within the time that the intervention would be completed. Inmates were invited but not required to participate in the class or to attend sessions. The jail education coordinator and instruction staff ensured that all Fit Fathers, Successful Families, Inside \& Out Program (FFFSIO) participants completed paper and pencil pretest before or at their first class.

Of the 112 jail participants, 65 completed both pretest and posttest (58\% pre/post completion rate). Information regarding participants completing both pretests and posttests were the following: $57 \%$ white $(n=37$; compared to $55 \%$ at pretest only); $30.8 \%$ Hispanic $(n=20$, compared to $26 \%$ at pretest); $3.1 \%$ Black ( $\mathrm{n}=2$ compared to $2.7 \%$ at pretest); and $1.5 \%$ multiracial/multiethnic ( $\mathrm{n}=1$; compared to $8.9 \%$ at pretest), and $1.5 \%$ American Indian/Alaskan Native ( $n=1$, compared to $2.7 \%$ at pretest). The mean age of fathers who completed posttests was 32.8 years, and ranged in age from 19 years to 63 years, compared to 32.6 years at pretest. The mean number of children per participant ranged 2.1, compared to 2.2 at pretest, with a range of 1 to 6 .

\section{The Program: Fit Fathers, Successful Families, Inside \& Out}

Fit Fathers, Successful Families, Inside \& Out Program (FFSFIO) is an integrated program that served fathers in a two-county region in the local jail and in an alcohol and drug treatment center in a small city in the Pacific Northwest from 2009 through June 2013. FFSFIO's programmatic goal was to prevent child abuse and reduce recidivism by improving parents' resilience. The program combined a fatherhood curriculum developed for criminal justiceinvolved fathers called Fit2bFathers (Maiorano,
2000) with yoga and mindfulness instruction. Prior to the inception of FFSIO in 2009, no formal or official parent education program (or mindfulness or yoga program) had been offered in the regional jail where this evaluation took place. The study was determined as exempt from the approval process by the Washington State University Institutional Review Board's Office of Research Assurances because all data were archival and evaluation was part of programming requirements and all identifying information had been removed.

A six-member instructor team comprised of parent educators and trained yoga instructors delivered classes to participants. Both parenting and yoga instructors received training from WSU Extension faculty, and from jail personnel. The training included establishing and maintaining appropriate boundaries with jail personnel, inmates, and other professionals. WSU Extension instructor trainings emphasized the role of both parenting educators and yoga teachers to model safe, trusting, and respectful relationships within the classroom environment. Additionally, Yoga Behind Bars, Street Yoga, and Living Yoga $($, organizations that train yoga teachers to effectively work with incarcerated and other marginalized populations, provided initial guidance as well as ongoing consultation to delivery of the yoga component. Yoga instructor training also addressed use of verbal instruction and no physical adjustment to students' poses (to adhere to jail policy).

Across three-to-four week time periods, participants received a total of 24 programming hours comprised of twelve, two-hour meetings. Table 1 provides an overview of both the FFSFIO parenting and yoga instruction content and structure. In each two-hour meeting, one parenting instructor and one yoga instructor were present. Class sizes ranged from 6 to 10 participants per program, in which participant groups met three to four days/week for two-hour sessions, for three to four weeks. In the first hour of each session, parent education sessions incorporated didactic learning, discussion, and occasional role plays of program content to accommodate adult learning. In each yoga session, which was delivered during the second 
class hour, a yoga instructor guided a centering activity, then led a physical yoga posture practice, and ended with a deep relaxation. During the first hour, yoga instructors participated in the parenting education portion of the session by listening and by contributing to discussions and often as a result incorporated some themes and discussion topics into the guided yoga class material. During the second hour, the parenting educator participated as a yoga student.

Table 1.

Fit Fathers Successful Families Inside Out (FFSFIO) Curriculum Overview

Parent Education Content and Structure

55-minutes instructor guided sessions; Centering; Community agreement; Experiential and didactic learning; Journaling between classes; Core Parent Education Modules* + Four Elective Modules + Guided Yoga Practice Structure

55-minute instructor guided sessions; Reflection/Yoga philosophy/Mindful Movement Instruction; Experimental learning; Breath instruction; Deep relaxation (5 minutes)

\begin{tabular}{|c|c|}
\hline \multicolumn{2}{|c|}{ *Core parenting Education Modules } \\
\hline Module & Content \\
\hline Introduction & $\begin{array}{l}\text { Overview of program; Community } \\
\text { Agreement }\end{array}$ \\
\hline Back to Basics & $\begin{array}{l}\text { Defining roles sometimes in } \\
\text { conflict as adults, partners in } \\
\text { relationships, and parents }\end{array}$ \\
\hline Setting Limits & $\begin{array}{l}\text { Guided discussion and activities } \\
\text { teaching positive discipline } \\
\text { strategies including giving } \\
\text { appropriate choices starting early }\end{array}$ \\
\hline Child & Overview of developmental stages \\
\hline Development & $\begin{array}{l}\text { and parents' role in helping create } \\
\text { supportive environments }\end{array}$ \\
\hline $\begin{array}{l}\text { Communicating } \\
\text { with Children }\end{array}$ & $\begin{array}{l}\text { Introduction of communication and } \\
\text { practice using responsive language }\end{array}$ \\
\hline Living & Assessment of wellness, personal \\
\hline Proactively & $\begin{array}{l}\text { balance, and goals for self and } \\
\text { family }\end{array}$ \\
\hline $\begin{array}{l}\text { Four Elective } \\
\text { Modules }\end{array}$ & $\begin{array}{l}\text { Participants selected from a list of } \\
\text { options: (1) Roles Rights \& }\end{array}$ \\
\hline & Responsibilities; (2) \\
\hline & Communicating 2; (3) Setting \\
\hline & Limits 2; (4) Healthy Living; (5) \\
\hline & Mindful Parenting; (6) Money \\
\hline & Management; (7) Career \\
\hline & Advancement. \\
\hline \multicolumn{2}{|c|}{\begin{tabular}{l}
\multicolumn{1}{c}{ Graduation } \\
Review of program session, optional guest speaker, \\
certificates distributed
\end{tabular}} \\
\hline
\end{tabular}

Yoga teachers each taught simple sequences that emphasized standing poses and limited advanced poses, due to a myriad of potential health issues characteristic and common among inmate populations. Yoga instructors offered modifications to poses to accommodate special needs. Each yoga portion of class began with a centering activity which provided a focus of attention for the students. Each yoga instructor taught at least five classic standing poses, such as tree pose, Warrior 1, Warrior 2, and Warrior 3 poses, side angle pose, and triangle pose, followed by floor poses such as bridge, and gentle supine twists. Standing poses required and cultivated each physical strength, flexibility and balance while building heat in the body and relieving tension. Within this structure, each instructor was given some flexibility to how they chose to weave in themes and concepts from the parenting education class sessions and from yoga philosophy.

Yoga instructors lead the class primarily from their own mat, and provided verbal cues to assist students with alignment. The protocol left much freedom for each yoga instructor to determine the sequence of postures, and the proportion of standing, seated, and supine postures. Most yoga instructors taught how to breathe with the diaphragm using a relaxed breath and/or the "three-part-breath." Other instructors also taught the ujayi breathing practice, in which the back of the throat is slightly constricted, making a faint "ahh" sound on the inhalation and exhalation, and it becomes a focus of attention. All classes ended in at least a 5-minute guided deep relaxation. Participants with injuries or other needs were provided with alternative poses, e.g. using support of chair, and in some cases were allowed to simply observe and listen to instruction while the remaining class practiced.

\section{Survey Administration and Measures}

Participants completed posttests either upon leaving the program facility (due to transfer or discharge) or completed the program during their last session. Participants received graduation or participation certificates only upon or after completing their posttest. Pretest and posttest information contained coded registration 
data; secondary data analysis did not contain any personal identifying information.

We assessed parental resiliency with three measures - Self Compassion Scale (SCS) (Neff, 2003), Distress Tolerance Scale (DTS) (Simons and Gaher, 2005), and Whole Person Survey (WPS) (Crawford, unpublished). We measured parenting with Fit2bFathers Scale (F2BS) (Maiorano, 2000). The first two measures have been used in similar mindfulness-based interventions such as Mindfulness Based Relapse Prevention (MBRP), and reflect internal mental states that correlate to resilience. Cronbach's alpha values report the reliability of the sub-scales.

Self-Compassion Scale (SCS). SelfCompassion is defined as an "orientation towards seeing the world, and the self, realistically, but kindly, and in a contextualized manner supportive of greater well-being" (Tanaka, et. al. 2001). The SCS, developed by Neff (Neff, 2003), is a 26-item, self-report validated scale that assesses overall selfcompassion based on six components: selfkindness vs. self-judgment, common humanity vs. isolation, mindfulness vs. over-identification. Scores on the Self-Compassion scale have been related to positive mental health outcomes (Neff \& Germe, 2013). Although the SCS had not previously been used among incarcerated populations (Neff, personal correspondence, May 9, 2015), the SCS represents an affectivecognitive stance that is facilitative of positively adaptive responses to personal adversity. As such, SCS promotes resilience and reflects an ability to curb emotional reactivity even during challenging experiences.

Out of the six subscales, Self-Kindness $(\alpha=$ $.66)$, Humanity $(\alpha=.75)$, Mindfulness $(\alpha=.78)$ are scored positively so that higher scores represent a more positive outcome. The remaining three subscales, Self-Judgment ( $\alpha=$ .78), Isolation $(\alpha=.76)$, and Over-Identification $(\alpha=.67)$, are scored negatively so that lower scores represent a more positive outcome. Participants rate items on a one- to five-point scale, with 1 = "Almost Never" and 5 = "Almost
Always." Sample items from each category of the SCS include "I try to be understanding and patient towards those aspects of my personality I don't like” (Self-Kindness); "When I see aspects of myself that I don't like, I get down on myself” (Self-Judgment); "When I feel inadequate in some way, I try to remind myself that feelings of inadequacy are shared by most people"(Common Humanity); "When I'm feeling down I tend to feel like most other people are probably happier than I am" (Isolation); "When something painful happens I try to take a balanced view of the situation" (Mindfulness); and, "When something painful happens I tend to blow the incident out of proportion" (Over-Identification).

Distress Tolerance Scale (DTS). The DTS, developed by Simons and Gaher (Simons \& Gaher, 2005), is a 15-item, self-report scale which is a personal internal assessment of one's ability to withstand difficult thoughts or emotions. This scale has four subscales: Tolerance $(\alpha=.71)$, Absorption $(\alpha=.69)$, Appraisal ( $\alpha=.77)$, and Regulation $(\alpha=.69)$. Participants rate items on a one- to five-point scale, with $1=$ "Strongly Agree" and $5=$ "Strongly Disagree." Sample items from the DTS include "Feeling distressed or upset is unbearable to me"(Tolerance), "I am ashamed of myself when I feel upset or distressed"(Appraisal), "My feelings of distress are so intense that they completely take over" (Absorption) and "I'll do anything to avoid feeling distressed or upset” (Regulation). In a prospective study of over 600 men, DTS scored negatively associated with alcohol use (Simons \& Gaher, 2005). The DTS was selected as an indicator of parental resilience because it assesses a person's ability to tolerate uncomfortable situations while still practicing emotional regulation. 
Table 2.

Paired Samples T-Test Results for Overall Scales and Subscales

\begin{tabular}{|c|c|c|c|c|c|c|c|}
\hline & etest & & & & & & \\
\hline Scales & $\underline{\mathrm{N}}$ & $\underline{\mathrm{M}}$ & $\underline{\mathrm{SD}}$ & $\underline{\mathrm{M}}$ & $\underline{\mathrm{SD}}$ & $\underline{\mathrm{t}}$ & $\mathrm{p}$ \\
\hline SCS Self-Kindness & 64 & 2.92 & 0.75 & 3.25 & 0.76 & 3.12 & .003 \\
\hline SCS Humanity & 64 & 3.03 & 0.89 & 3.35 & 0.71 & 2.89 & .005 \\
\hline SCS Mindfulness & 64 & 3.29 & 0.87 & 3.42 & 0.80 & 1.21 & .229 \\
\hline SCS Self-judgment ${ }^{t}$ & 65 & 3.31 & 0.76 & 2.96 & 0.77 & -3.14 & .003 \\
\hline SCS Isolation $^{\mathrm{t}}$ & 64 & 3.22 & 0.86 & 2.86 & 0.82 & -3.36 & .001 \\
\hline SCS Over-identification $^{\mathrm{t}}$ & 65 & 3.16 & 0.85 & 2.86 & 0.84 & -2.79 & .007 \\
\hline SCS Overall & 65 & 2.92 & 0.56 & 3.21 & 0.52 & 4.25 & $<.001$ \\
\hline DTS Tolerance & 62 & 3.05 & 1.02 & 3.25 & 1.02 & 1.49 & .141 \\
\hline DTS Absorption & 62 & 2.80 & 1.03 & 3.19 & 0.94 & 2.81 & .007 \\
\hline DTS Appraisal & 62 & 3.11 & 0.82 & 3.22 & 0.82 & 0.92 & .364 \\
\hline DTS Regulation & 62 & 2.59 & 1.00 & 2.78 & 1.10 & 1.28 & .205 \\
\hline DTS Overall & 62 & 2.88 & 0.81 & 3.11 & 0.83 & 2.01 & .049 \\
\hline WPS Breath & 59 & 2.48 & 0.98 & 3.37 & 0.96 & 5.42 & $<.001$ \\
\hline WPS Mindfulness & 59 & 2.76 & 1.13 & 3.53 & 0.94 & 4.64 & $<.001$ \\
\hline WPS Spirit & 59 & 2.71 & 1.06 & 3.39 & 0.92 & 4.83 & $<.001$ \\
\hline WPS Physical & 59 & 3.24 & 0.95 & 3.50 & 0.84 & 2.05 & .045 \\
\hline WPS Overall & 59 & 2.85 & 0.86 & 3.45 & 0.77 & 4.93 & $<.001$ \\
\hline Fit2bFathers Overall & 65 & 4.79 & 0.42 & 5.13 & 0.36 & 6.41 & .000 \\
\hline
\end{tabular}

Note: DTS = Distress Tolerance Scale (Simons \& Gaher, 2005); SCS = Self Compassion Scale (Neff, 2003); WPS = Whole Person Survey. ${ }^{\mathrm{t}}$ The SCS self-judgment, isolation, and over-identification subscales are scored so that lower scores indicate higher positive mental health. For all other scales, higher scores indicate higher positive mental health.

Whole Person Survey (WPS). The WPS, modified by the first author with permission from Joseph LePage, Integrative Yoga Therapy ${ }^{\circledR}$, contains four subscales that assesses expected physical and emotional effects related to practicing yoga - Physical $(\alpha=.84)$, Breath $(\alpha$ $=.66)$, Mindfulness $(\alpha=.83)$, and Spirituality ( $\alpha$ $=.81$ ) (Crawford, unpublished). Developed from yoga philosophy, specifically as a reflection of four dimensions of a person's human experience, the scale shows internal consistency reliability but has not been tested on other populations for external validity. The scale was designed to reveal a person's ability to pay attention to their internal processing of physical, mental/emotional, and spiritual experiences, which are hypothesized to positively correlate with emotional regulation, an indicator of parental resilience. Participants rated items on a one- to five-point scale, with $1=$ "Almost Always" and 5 = "Almost Never". Sample items from the WPS include "I have tools and skills to reduce physical pain in my body and to bring myself towards balance" (Physical), "I notice my breath to assess how stressed I am" (Breath), and "I can monitor my thoughts, sensations, and emotions without judging them.”(Mind).

Fit2bFathers Program Scale (F2BF). The F2BF, developed by Maiorano (Maiorano, 2000), contains questions related to knowledge of positive parenting and how to support positive child development, in addition to selfassessments of the value and confidence participants place in their own parental role. Participants rate items on a one- to six-point 
scale, with 1 = "Strongly Disagree" and $6=$ "Strongly Agree." Sample items from the F2BF include "Children who are given choices are better at making choices on their own", "Being a parent is important to me", and "I have a good relationship with my youngest child." Cronbach's alpha of the Fit2bFathers Scale is .63 for pretest and .53 for posttest.

Analyses Paired sample t-test analysis (using IBM SPSS Statistics 21 software) tested for pretest to posttest changes on parental resiliency (assessed by the WPS, SCS, and DTS) and parenting scales. We conducted 18 t-tests in totals (4 scales, and 14 subscales). To maintain a family-wise Type 1 error rate of .05 , each pairwise t-test result was evaluated at a percomparison Bonferroni corrected $p$-value of .003 .

\section{Results}

The results of paired t-test analyses, as reported in Table 2, show that program participants scored significantly higher on three overarching scales on posttest than on pretest. Participants' scores improved on the overall SCS scale $(t=$ $4.25, p<.001)$, overall WPS scale $(t=4.93, p<$ $.001)$, and Fit2bFathers Program Scale $(t=6.41$, $p<.001)$. These results indicate that they reported significant changes in their ability to treat themselves kindly, feel more connected to the physical, emotional, and spiritual aspects of themselves, and demonstrate knowledge of positive parenting practices. Program participants' scores also improved on a total of six subscales from pretest to posttest. Participants scored significantly lower on the SCS Self-Judgment subscale $(\mathrm{t}=-3.14, p=$ $.003)$ and SCS Isolation subscale $(t=-3.36, p=$ .001 ), indicating less self-criticism, and feeling less alone in their struggles. Additionally, participants scored significantly higher at posttest on SCS Self-Kindness subscale ( $t=$ 3.12, $p=.003)$, WPS Breath subscale $(t=5.42$, $p<.001)$, WPS Mindfulness subscale $(t=4.64$, $p<.001)$, and WPS Spirituality subscale $(t=$ 4.83, $p=.001$ ). The pretest to posttest changes for the overall DTS scale and its and other subscales were positive in direction but not significant in magnitude.

\section{Discussion}

The FFSFIO program intertwined parenting education with yoga and mindfulness with the intention that participants parental resilience, or capacity to practice self-restraint and model selfregulation, would increase. We hypothesized that participating in the FFSIO program would result in improved resilience and parenting knowledge among a high-risk population of incarcerated fathers. The evaluation showed positive change in two of the three recognized indicators of resilience scales. Results provided partial support for our hypothesis that participation in the program would increase parental resilience, and partially supported our hypothesis that participation in the program would improve parenting knowledge among incarcerated fathers. In six of the 14 subscales measuring resiliency, participants showed significant improvement. Although the DTS scale and some of the subscale changes were not statistically significant, the findings of this study provide preliminary evidence that intensive yoga practice combined with parenting education could change key indicators related to resilience for high risk offenders.

These results also provide preliminary evidence that yoga and mindfulness combined with parenting education may benefit incarcerated fathers personally, in terms of self-awareness, resilience and parenting knowledge, which may in turn improve actual parenting behaviors. The outcomes also suggest that physical and intentional, guided yoga practices may have built participants' capacities for assimilating new ideas and concepts, retaining and applying information shared in both the yoga and parent education sessions. Given the growing popularity of yoga and the availability of yoga instructors trained to teach in specialized settings, yoga shows promise for offering an accessible intervention with large potential returns.

As mentioned earlier, the yoga sessions took place after parenting education classes. This sequencing worked within the jail schedule which permitted classes after the lunch hour. Conducting the parenting education sessions 
before yoga, rather than holding the yoga portion in the first hour, provided more time for participants to digest their lunch. The yoga sessions placed after the parenting education sessions also allowed for students to mentally 'digest' or process and assimilate the program content and to integrate the mental information while relieving physical or mental stress through the physical exercise that is part of the hatha yoga practice. The design of the second teacher modeling as "a student" during his/her nonteaching hour, although not explicitly studied, may also have contributed to the program's successful results.

\section{Limitations}

Our study had several limitations: First, the study design did not include a control group. Inclusion of a control group reduces bias in the study, thereby increasing the validity of the findings. Our program design limited our ability to test for its impact in comparison to a parenting education-only intervention, mindfulness-only, and no-intervention groups.

Second, because of the transient and temporary nature of stays in jail, not all participants completed both pretest and posttest. Because the average jail stay is 7-10 days, some program attrition was anticipated. This reduced the sample size included in the final analysis which affected our power to detect smaller effect sizes. Third, we were only able to test short-term change in resilience and parenting knowledge, not longer-term parenting skills or recidivism. Forth, our program design did not measure variables such participant buy-in to the program, the quality of partnerships with host jail and partner agencies, instruction quality, or variations in dosage that participants received. We speculate that each variable may have contributed to these results. Last, the results are based on inmates' self-assessments that may not accurately reflect their actual behavior as fathers. We recommend that future studies collect third party-member observations from social workers, parole and/or probations, and spouses, partners, and/or other family members to provide further evidence of behavior changes among inmates.
In another study in which men received only F2BF parenting intervention in an Ohio jail, overall F2BF scores improved significantly from 5.01 to 5.31 (Maiorano \& Futris, 2005). This implies that results of this intervention group are comparable with outcomes for participants in who received the Fit2BFathers parenting intervention only. However, Cronbach's alpha of the Fit2bFathers scale was .63 for pretest and .53 for posttest. As Cronbach's alpha of .70 is considered acceptable and a score of .80 is preferable, this makes the Fit2bFather parenting scale reliability sufficiently low to decrease power in detecting program effects. While future studies that select a parenting tool with better reliability would give a more accurate estimate of program effects of parenting knowledge competencies, the authors believe the measure still demonstrates and points to a commitment to and enthusiasm for parenting, and that these findings combined provide evidence that even high-risk adults can learn and cultivate emotional regulation, increase compassion for and connection to themselves and other family members, and develop conscientious parenting skills.

Even with the limitations, these promising study results lead us to believe that yoga practice, combined with parenting education, could affect key indicators related to parental resilience and parenting skills among low and high risk offenders, and that a guided and modeled yoga practice can enhance participants' ability to effectively develop resiliency skills. Given the availability and affordability of qualified yoga instructors, and the growing need for rehabilitative program delivery options (Duncombe et. al., 2005), these study results provide rationale for conducting more rigorous analysis of similar programs with variations to guide and enhance future program delivery and outcomes. Additional positive outcomes, as programming and evaluation rigor increase, would justify replicating similar programs that are broader in scope and scale.

\section{Recommendations for Future Studies}

Specific future research focus areas could include implementing and comparing parenting education-only groups, parenting education-with 
yoga instruction groups, and parent groups who did not participate in the program to determine whether these changes significantly differ between groups. Additionally, data collected from correctional officers, social workers, and/or family members could provide further evidence of whether and how attitudinal changes or internal shifts in participants are taking effect in terms of behavioral changes. The authors recommend that future studies also track both recidivism rates, and participants' children's behavioral outcomes in the short-, medium-, and long-term.

\section{ACKNOWLEDGEMENTS}

This study was supported through a Council for Children and Families and Washington State Department of Early Learning grant. Yoga Behind Bars, Street Yoga, and Living Yoga $($, organizations that promote yoga for marginalized populations, each provided initial staff trainings and ongoing consultations that informed program design and delivery. The Chelan County Regional Jail staff and the dedicated FFSFIO instructor team made this project not only possible but successful. In 2013, the Fit Fathers, Successful Families, Inside Out (FFSFIO) program changed to Resilient Families Inside Out (RFIO) to reflect that it serves both men and women at additional locations.

\section{References}

Amaro, H., Spear, S., Vallejo, Z., Conron, K. \& Black, D. S. (2014). Feasibility, Acceptability, and Preliminary Outcomes of a Mindfulness-Based Relapse Prevention Intervention for Culturally-Diverse, Low-Income Women in Substance Use Disorder Treatment. Substance Use \& Misuse, 49, 547-559.

Arévalo, S., Prado, G., \& Amaro, H. (2007). Spirituality, sense of coherence, and coping responses in women receiving treatment for alcohol and drug addiction. Evaluation and Program Planning, 31, 113-123.

Bahr, S.J., Armstrong, A.H., Gibbs, B.G., Harris, P.E. \& Fisher, J.K. (2005). The reentry process: How parolees adjust to release from prison [Electronic version]. Fathering: A Journal of Theory, Research, \& Practice about Men as Fathers, 3(3), 243-265.

Becker, A.L. (2015, January 20). The long reach of childhood trauma. The Connecticut Mirror. Retrieved June 9, 2015 from http://ctmirror.org

Bowen, S., Witkiewitz, K., Dilworth, T. M., Chawla, N., Simpson, T. L., Ostafin, B. D, Larimer, M. E, Blume, A.W., Parks, G. A., \& Marlatt, G. A. (2006). Mindfulness meditation and substance use in an incarcerated population. Psychology of Addictive Behaviors, 20(3), 343-347. doi: 10.1037/0893-164X.20.3.343

Browne, C.H. (2014). The Strengthening Families Approach and Protective Factors Framework: Branching out and reaching deeper. Washington, DC: Center for the Study of Social Policy. Retrieved July 8, 2015 from http://www.cssp.org/reform/strengtheningfamilies/2014/The-Strengthening-Families-Approachand-Protective-Factors-Framework_Branching-Out-and-Reaching-Deeper.pdf

Child Welfare Information Gateway, Children's Bureau, FRIENDS National Resource Center For Community-Based Child Abuse Prevention, 2008 retrieved October 15, 2013 from https://www.childwelfare.gov/pubs/res_packet_2008/ch_two_parental.cfm

Chopra, D., \& Simon, D. (2004). The seven spiritual laws of yoga. Hoboken, NJ: John Wiley \& Sons.

Coatsworth, J. D., Duncan, L. G., Greenberg, M. T., and Nix, R. L. (2010). Changing parent’s mindfulness, child management skills and relationship quality with their youth: Results from a randomized pilot intervention trial. Journal of Child and Family Studies, 19, 203-217.

Comfort, M. (2007). Punishment beyond the legal offender. Annual Review of Law and Social Science, 3, 297-296. 
Author, Shrestha, G., Placone, P. \& Author., (2013). Mindful parenting curriculum components that support parental resilience. National Council on Family Relations Annual Conference, San Antonio, TX. Poster presentation.

Cuffe, S. P., McKeown, R.E., Addy, C. L. \& Garrison, C. Z. (February 2005). Family psychosocial risk factors in a longitudinal epidemiological study of adolescents. Journal of American Academic Child Adolescent Psychiatry, 44, 121-129.

Dafoe, T. \& Stermac, L. (2013). Mindfulness meditation as an adjunct approach to treatment within the correctional system. Journal of Offender Rehabilitation, 52 (3), 198-216.

Day, A. \& S Casey, S. (2009). Values in forensic and correctional psychology. Aggression and Violent Behavior(14), 232-238.

Duncan, L. G., J. D. Coatsworth, and Greenberg, M. T. (2009). A Model of Mindful Parenting: Implications for Parent-Child Relationships and Prevention Research. Clinical Child and Family Psychology Review, 12(3), 255-270. doi:10.1007/s10567-009-0046-3.

Duncan, L. G, Coatsworth, J. D., \& Greenberg, M. T. (2009), Pilot study to gauge acceptability of a mindfulness-based, family-focused preventive intervention, Journal of Primary Prevention, 30, 605-618.

Duncombe, E., Kamorosky, D., Wong-Kim, E., \& Turner, W.(2005). Free Inside: A program to help inmates cope with life in prison at Maui Community Correctional Center. Californian Journal of Health Promotion, 3 (4), 48-58.

Eddy, M. Martinez, C. R., Schiffmann, T., Newton, R., Olin, L., Leve, L., Foney, D. M., \& J. M. Shortt. (November 2008). Development of a multisystemic parent management training intervention for incarcerated parents, their children, and families. Clinical Psychologist, 12(3), 86-98. doi: $10.1080 / 13284200802495461$

Fix, R. L. \& Fix, S. T. (2013). The effects of mindfulness-based treatments for aggression: A critical review. Aggression and Violent Behavior, 18, 219-227.

Garrett, M., \& Carroll, J. (2000). Mending the broken circle: Treatment of substance dependence among Native Americans. Journal of Counseling \& Development, 78(4), 379.

Gordon, J.C. (2002). Beyond knowledge: Guidelines for effective health Promotion messages. Journal of Extension [On-line], 40(6) Article 6FEA7. Retrieved June 16, 2015 from http://www.joe.org/joe/2002december/a7.php

Griffin, K.W., Botvin, G. J., Scheier, L. M., Diaz, T. \& Miller, N. L. (2000). Parenting practices as predictors of substance use, delinquency, and aggression among urban minority youth: Moderating effects of family structure and gender. Psychology of Addictive Behaviors, 14, 174184. doi: 10.1037//0893-164X.14.2.174

Garfinkel, I., McLanahan, S., \& Harknett, K. (2005). Children's elevated risk of asthma in unmarried families: Underlying structural and behavioral Mechanisms. Working Paper \#2005-01-FF. Princeton, NJ: Center for Research on Child Well-being, 19-27. Retrieved June 16, 2015 from http://crcw.princeton.edu/workingpapers/WP99-11-FF-Garfinkel.pdf

Hoffmann, J. P. (2002). The community context of family structure and adolescent drug use. Journal of Marriage and Family 64, 314-330. DOI: 10.1111/j.1741-3737.2002.00314.x

Howells, K., Day, A., Williamson, P., Bubner, S., Jauncey, S., Parker, A., \& Heseltine, K. (2005). Brief anger management programs with offenders: Outcomes and predictors of change. The Journal of Forensic Psychiatry \& Psychology, 16(2), 296-311.

Howells, K., Tennant, Al, Day, A., \& Elmer, R.(2010). Mindfulness in forensic mental health: Does it have a role? Mindfulness 1, 4-9.

Karberg, J. C. \& D. J. James. Substance Dependence, Abuse, and Treatment of Jail Inmates, 2002. NCJ 209588. Washington, D.C.: U.S. Department of Justice, Bureau of Justice Statistics, 2005. bjs.ojp.usdoj.gov/content/pub/pdf/sdatji02.pdf.

Javnbakht, M, Kenari, R. H, \& Ghasemi, M. (2009). Effects of yoga on depression and anxiety of women. Complementary Therapies in Clinical Practice, 15(2), 102-104. doi:10.1016/j.ctcp.2009.01.003 
Kjellstrand, J.M. \& Eddy, J.M.(2011). Parental incarceration during childhood, family context, and youth problem behavior across adolescence. Journal of Offender Rehabilitation, 50, 18-36. DOI $10.11080 / 10509674.2011 .536720$

Keng, S., Smoski, M. J., \& Robins, C. J., (2011). Effects of mindfulness on psychological health: A review of empirical studies. Clinical Psychology Review, 31, 1041-1056.

Kubiak, S. P., Fedock, G., Tillander, E., Kim, W. J., Bybee, D. (2014). Assessing the feasibility and fidelity of an intervention for women with violent offenses, Evaluation and Program Planning, 42, $1-10$

Lavinge, N. G., Family \& reentry: Capitalizing on the often untapped role of family in successful reentry. Procedings of International Community Corrections Association Annual Conference presentation, September 14, 2009. Retrieved June 16, 2015 from http://www.iccaweb.org/documents/N.LaVigne_FamilyAndReentry.pdf

Lilly, M., \& Hedlund, J., (2010). Yoga therapy in practice: Healing sexual abuse with yoga. International Journal of Yoga Therapy, 20, 120-130.

MacDonald, E.E., \& Hastings, R.P. (2010). Mindful parenting and care involvement of fathers of children with intellectual disabilities. Journal of Child \&Family Studies, 19, 236-240.

Maiorano, J.J.(2000). Fit 2-b FATHERS. Retrieved June 16, 2015 from http://fcs.osu.edu/f2bf/index.php.

Maiorano, J.J. (2001). Fit 2-b FATHERS. Journal Of Extension [On-line], 39(5). Article 5IAW7. Retrieved June 16, 2015 from http://www.joe.org/joe/2001october/iw7.php

Maiorano, J.J., \& Futris, T.G. (2005). Fit 2-B FATHERS: The effectiveness of extension programming with incarcerated fathers. Journal Of Extension [On-line], 43(5). Article 5FEA7. Retrieved June 16, 2015 from http://www.joe.org/joe/2005october/a7.php

Marlow, E., Nyamathi, A., Grajeda, W.T., Bailey, N., Weber, A., \&Younger, J. (2011). Nonviolent communication training and empathy in parolees. Journal of Correctional Health Care, 18(1). 8-19.

McBride, B. A., Schoppe-Sullivan, S.K., \& Ho, M-H. (2005). The mediating role of fathers' school involvement on student achievement. Applied Developmental Psychology, 26, 201-216. doi:10.1016/j.appdev.2004.12.007|

Mitchell, H., From recession to recovery: Intersection of policy and opportunity. Proceedings of International Community Corrections Association D.C. Public Policy Forum March 23, 2010. Retrieved June 16, 2015 from http://www.iccaweb.org/documents/HMitchellICCAPresentation.pdf

Moore, A.R., \& Clement, M.J (1998). Effects of parenting training for incarcerated mothers. Journal of Offender Rehabilitation, 27 (1), -257-72.

National Center for Complementary and Integrative Health, (2013). Yoga for Health. NCCIH Pub No. D472, retrieved April 28, 2015 from https://nccih.nih.gov/health/yoga/introduction.htm

National Fatherhood Initiative (2004). Family structure, father closeness, \& drug abuse. Gaithersburg, MD: National Fatherhood Initiative: 20-22.

Neff, K.D. (2003). The development and validation of a scale to measure self-compassion Self and Identity, 1529-8876, 2(3), 223 - 250. 10.1080/15298860390209035

Neff, K. D., \& Germer, C. K. (2013). A pilot study and randomized controlled trial of the mindful self-compassion program. Journal Of Clinical Psychology, 69(1), 28-44.

O'Connell, M.E., Boat, T., \& Warner, K.E., Editors, (2009). Preventing mental, emotional, and behavioral disorders among young people: Progress \& possibilities. Policy brief for researchers. Retrieved June 15, 2015 from http://www.iom.edu/reports/2009/preventing-mentalemotional-and-behavioral-disorders-among-young-people-progress-and-possibilities.aspx

O’Connor, T., L. Davies, Dunn, J., \& Golding, J.(2000). Differential distribution of children's accidents, injuries and illnesses across family type. Pediatrics, 106(68). doi: 10.1542/peds.106.5.e68 Retrieved June 16, 2015 from http://pediatrics.aappublications.org/cgi/reprint/106/5/e68.pdf 
Phillips, S.D., Gleeson, J.P., \& Waites-Garrett, M. (2009). Substance-abusing parents in the criminal justice system: Does substance abuse treatment improve their children's outcomes? Journal of Offender Rehabilitation, 48 (2), 120-138, DOI: 10.1080/1050967080240925.

Pilkington , K., Kirkwood, G., Rampes, H., \& Richardson, J. (2005). Yoga for depression: The research evidence. Journal of Affective Disorders, 89, 13-24. doi:10.1016/j.jad.2005.08.013

Pratt, C., \& Bowman., S. (2008). Principles of Effective Behavior Change. Journal of Extension 46(5). Article 5FEA2. Retrieved June 16, 2015 from http://www.joe.org/joe/2008october/a2.php

Rybak, C., \& Duskar, M. (2010). Enriching group counseling through integrating yoga concepts and practices. Journal of Creativity in Mental Health, 5, 3-14. 10.1080/15401381003626782

Samuelson, M., Carmody, J., Kabat-Zinn, J., \& Bratt, M.A. (2007). Mindfulness-based stress reduction in Massachusetts correctional facilities. The Prison Journal, 87, 254-268. doi: 10.1177/0032885507303753 Retrieved June 16, 2015 from http://tpj.sagepub.com/content/87/2/254.refs

Sedlak, A.J. \& Broahurst, D.B. (1996). The third national incidence study of child abuse and neglect: Final Report. U.S. Department of Health and Human Services. National Center on Child Abuse and Neglect. Washington, D.C., Retrieved June 16, 2015 from http://www.childwelfare.gov

Settersten, R.A., \& Cancel-Tirado, D. (2010). Fatherhood as a hidden variable in men's development and life courses. Research in Human Development, 7(2), 83 - 102. doi: 10.1080/15427609.2010.481520

Shonin, E., Gordon, W.V., Slade, K., \& Griffiths, M.D. (2013). Mindfulness and other Buddhist-derived interventions in correctional settings: A systemic review. Aggression and Violent Behavior, 18, 365-272.

Simons, J.S., and Gaher, R. M. (2005). The distress tolerance scale: development and validation of a selfreport measure. Motivation and Emotion, 29(2), 83-102. doi: 10.1007/s11031-005-7955-3

Smith, C., Hancock, H., Blake-Mortimer, J., \& Eckert, K. (2006). Randomized comparative trial of yoga and relaxation to reduce stress and anxiety. Complementary Therapies in Medicine, 15(2), 77-83. doi:10.1016/j.ctim.2006.05.001

Tanaka, M., Wekerle, C., Schmuck, M. L., Paglia-Boak, A., \& MAP Research Team (2011). The ages among childhood maltreatment, adolescent mental health, and self-compassion in child welfare adolescents. Child Abuse \& Neglect, 35, 887-898.

The Focusing Institute (2015). Nyak, NY (http://www.focusing.org)

Trauma Center at Justice Resource Institute (n.d.). Yoga as a complementary treatment for chronic PTSD. Downloaded from http://www.traumacenter.org/research/Yoga_Study.php

Author Information

*Jennifer K. Crawford, C.Y.T., M.P.A.

Educator \& Assistant Professor, Family \& Human

Development

WSU Chelan/Douglas County Extension

400 Washington Street

Wenatchee, WA 98801

Phone: 509-667-6544, Fax: 667-6561

crawfordj@wsu.edu

* corresponding author

Gitanjali Shrestha, M.A.

Graduate Student

Washington State University

Department of Human Development

Johnson Tower 501 
Pullman, WA 99164-4852

Gitanjali.shrestha@email.wsu.edu

Laura G. Hill, Ph.D.

Washington State University

Professor and Chair, Human Development

Prevention Science Graduate Faculty

Johnson Tower 501

Pullman, WA 99164-4852

Phone: (509) 335-8478

laurahill@wsu.edu 